\title{
Effects of p53 Codon 72 and MDM2 SNP309 Polymorphisms on Gastric Cancer Risk among the Iranian Population
}

\author{
Mohammad-Taher Moradi ${ }^{1,2}$, Zivar Salehi²*, Keyvan Aminian $^{3}$, Abbas \\ Yazdanbod $^{4}$
}

\begin{abstract}
Background: Development of gastric cancer (GC) is a multistep process that requires alterations in the expression of oncogenes and tumor suppressor genes, occurring over several decades. The $\mathrm{p53}$ tumor suppressor protein is involved in cell-cycle control, apoptosis and DNA repair. One of the most important regulators of p53 is MDM2, which acts as a negative regulator in the p53 pathway. Based on the key role of p53 and MDM2 in tumor suppression, polymorphisms that cause change in their function might affect cancer risk. We therefore elevated associations of the polymorphisms of p53 (R72P) and MDM2 (SNP309) with GC in Iran. Materials and Methods: A total of 104 patients with gastric cancer and 100 controls were recruited. Genomic DNA was extracted from fresh gastric samples. Genotyping of the $\mathbf{p 5 3}$ and MDM2 genes was performed using allele specific PCR (AS-PCR). Results: There was no significant difference between the p53 codon 72 polymorphism distribution in control and patient groups $(\mathrm{p}=\mathbf{0 . 5 4})$, but the $\mathrm{G}$ allele of MDM2 was found to be over-represented in patients ( $p=0.01$, Odds Ratio=2. 08,95\% Confidence Interval= 1.37-4.34). Conclusions: The p53 R72P seems not to be a potential risk factor for development of GC among Iranian patients, but our data suggest that MDM2 SNP309 might modify the risk related to GC.
\end{abstract}

Keywords: Gastric cancer - p53 codon 72 - MDM2 SNP309 - Genetic Polymorphism

Asian Pac J Cancer Prev, 15 (17), 7413-7417

\section{Introduction}

Gastric carcinogenesis is a complex, multistep and multifactorial process, which the majority of cases are thought to be caused by environmental factors that cause damage in the mucosa and inhibit its capability to repair itself. This response is controlled, partly, by regulatory factors that are produced with proto-oncogenes and tumor suppressor genes (Tahara, 1993; Oh et al., 2014). In Iran, the most common deadly cancer is gastric adenocarcinoma, which has a wide variation of death rate in southern Iran 3.6 per 100,000 per year as compared to a rate of 8.4 per 100,000 in East Azerbaijan, northern Iran (Fallah, 2007; Atrkar-Roushan et al., 2013; Somi et al., 2014).

The p53 protein, was known as 'the guardian of the genome', and is an important regulator of cellular growth control (Harris and Hollstein, 1993). Clinical studies and mouse models have shown that p53 is mutated in 50\% of human cancers, and functionally inactivated in much more (Marine et al., 2006). More than 200 SNPs (germline variants) have been recognized in $\mathrm{p} 53$; in contrast to tumor-associated mutations, most of these p53 SNPs have, improbably, biological effects. Based on the key role of p53 in tumor suppression, the polymorphisms that cause changes in p53 function might affect cancer risk, progression and/or response to treatment (Whibley et al., 2009). The p53 codon 72 polymorphism (p53 R72P) alter, non-conservatively, an arginine (R72) to a proline (P72) at amino acid 72 that causes structural changes of the protein giving rise to variants of separate electrophoretic mobility (Harris et al., 1986; Matlashewski et al., 1987). This SNP takes place in a proline-rich region of $\mathrm{p} 53$, which is pivotal for the apoptotic functions of this protein (Walker and Levine, 1996; Sakamuro et al., 1997). One of the pivotal points of the p53 pathway is the MDM2 protein (Bond et al., 2005a). MDM2 (murine double minute 2) was discovered on double minute chromosomes in a derived cell line of NIH-3T3 cells (Fakharzadeh et al., 1991; Momand et al., 1992). MDM2, as a p53 target gene, is part of E3 ubiquitin ligases family that includes a RING [really interesting new gene] domain and for p53 degradation act as the major E3 ubiquitin ligase (Pei et al., 2012). The MDM2 protein binds to $\mathrm{p} 53$ and regulates that by changing its location, stability and activity(Poyurovsky and Prives, 2006). Consistent with MDM2 role as a negative regulator of $\mathrm{p} 53$, altering its levels has been

${ }^{1}$ Medical Biology Research Center, Kermanshah University of Medical Sciences, Kermanshah, ${ }^{2}$ Dept of Biology, Faculty of Sciences, University of Guilan, ${ }^{3}$ Guilan University of Medical Sciences (GUMS), Rasht, ${ }^{4}$ Ardabil University of Medical Sciences, Ardabil, Iran*For correspondence: geneticzs@yahoo.co.uk 
shown in many mouse models to affect p53-dependent tumor suppression (Poyurovsky and Prives, 2006). MDM2 level is crucial for p53 tumor suppression, and even a moderate change in $M D M 2$ levels could affect cancer in mice and a naturally occurring sequence variation in the $M D M 2$ promoter/enhancer region brings about modifying expression of the MDM2 protein, and affects p53 tumor suppression and ,eventually, causes cancer (Bond et al., 2004). Upon Bond et al. report, SNP 309 (rs2279744, $\mathrm{T}>\mathrm{G}$ ) downstream from $M D M 2$ intron 1, cause disruption of Sp1 regulatory element and formation of the T allele, therefore, has a conspicuously lower promoter activity in comparison with the $\mathrm{G}$ allele (Bond et al., 2004; Tian et al., 2013).

The present study aimed to examine the association between p53 and MDM2 polymorphisms and gastric cancer risk.

\section{Materials and Methods}

\section{Participants}

Gastric biopsies were obtained from 104 people with a diagnosis of gastric cancer and 100 cancer-free controls matched for age and sex were also evaluated. GC patients were recruited between May 2011 and June 2012. All registered subjects underwent endoscopy, and endoscopic findings were reviewed by two experienced endoscopists. The specimens were immediately frozen and stored at $-70^{\circ} \mathrm{C}$ until DNA extraction. Informed consent was obtained from all participants and ethical principles of the Helsinki Declaration were followed.

\section{Genomic DNA extraction}

Genomic DNA was extracted from endoscopic biopsy specimens. Tissue samples were suspended in $500 \mu 1$ of extraction buffer containing $2 \mathrm{mM}$ EDTA, 400 $\mathrm{mM} \mathrm{NaCl}$ and $10 \mathrm{mM}$ Tris- $\mathrm{HCl}(\mathrm{pH} \mathrm{8.0)}$. The mixture was incubated at room temperature for $20 \mathrm{~min}$. The solution was incubated at $55^{\circ} \mathrm{C}$ overnight, after addition of Proteinase $\mathrm{K}$ and sodium dodecyl sulfate (400 ng and $0.6 \%$, respectively). DNA extraction was done by GPP solution kit (Gen Pajoohan, Iran) as previously described. (Moradi et al., 2013) Extracted DNA was observed and confirmed by electrophoresis on $0.1 \%$ agarose gel containing etidium bromide. The concentration and purity of DNA were assessed with a Nanodrop (Thermo) with $260 / 280$ measurement ratio and at the wavelength of 260 and $280 \mathrm{~nm}$. Extracted DNA was stored at $-70^{\circ} \mathrm{C}$ until use.

\section{Polymorphism analysis}

For genotyping of the P53 and MDM2 ASPCR were used. For p53 R72P genotyping, two independent polymerase chain reaction (PCR) assays for each allele were used. Genomic DNA amplified by PCR using primers that detect p53 codon 72 in the proline form (5'-GCCAGAGGCTGCTCCCCC-3'; 5' CGTGCAAGTCACAGACTT-3') and arginine form (5' TCCCCC T T GCCG TCCCA A - 3'; 5'-CTGGTGCAGGGGCCACGC-3') according to the procedure described by Storey et al. (1998). (Storey et al., 1998)
MDM2 SNP309 (rs2279744, T>G) genotypes were analyzed using two independent PCR assays for each allele, modified from a technique described by Menin et al. (2006) (Menin et al., 2006). The procedure was performed using primer pairs specific for the two alleles. Primers F1 (5'-GGATTTCGGACGGCTCTC-3') and R1 (5'-TCCGGACCTCCCGCGCCGA-3') were used to amplify the 121-bp wild-type allele (T), and primers F2 (5'-GTTTTGTTGGACTGGGGCTA-3') and R2 (5'-ATCCGGACCTCCCGCGCCGC-3') were used to amplify the 168-bp mutant allele (G).

The amplification procedure was carried in a total reaction volume of $25 \mu \mathrm{l}$, containing $2.5 \mu \mathrm{l} 10 \mathrm{X}$ PCR buffer, $2 \mu$ l deoxy ribonucleotide triphosphates (1.25 $\mu \mathrm{mol} / \mathrm{L}), 0.5 \mu \mathrm{l} \mathrm{MgCl}_{2}(25 \mathrm{mmol} / \mathrm{L}), 1.25 \mu \mathrm{l}$ of each $\operatorname{primer}(25 \mathrm{mmol} / \mathrm{L}), 15.3 \mu \mathrm{l} \mathrm{dH}_{2} \mathrm{O}, 2 \mu \mathrm{l} \mathrm{DNA}(100 \mathrm{ng} / \mu \mathrm{l})$ and $0.2 \mu \mathrm{l} \mathrm{Taq} \mathrm{DNA} \mathrm{polymerase} \mathrm{(5} \mathrm{U/ \mu l)} \mathrm{(Biflux,} \mathrm{Japan).}$

After an initial denaturation at $94^{\circ} \mathrm{C}$ for $3 \mathrm{~min}$, the DNA was amplified by 35 cycles of $94^{\circ} \mathrm{C}$ for $30 \mathrm{Sec}, 60^{\circ} \mathrm{C}$ for $30 \mathrm{~s}$ and $72^{\circ} \mathrm{C}$ for $30 \mathrm{~s}$, with a final extraction at $72^{\circ} \mathrm{C}$ for $5 \mathrm{~min}$ on the Mini PCR (Bio-Rad), then the products electrophoresed on a $2 \%$ agarose gel, to allow detection by ethidium bromide staining. All assays were conducted blindly by two researchers without the knowledge of the case or control status. For quality control, a random of 5\% of samples was repeated with $100 \%$ concordance.

\section{Statistical analysis}

All statistical analyses were performed using MedCalc statistical software (Version 12.1, Mariakerke, Belgium). Differences in genetic distributions between patients and the controls were calculated by Pearson's chi-square $\left(\chi^{2}\right)$ test. Odds ratios (OR) and $95 \%$ confidence intervals $(95 \% \mathrm{CI})$ were estimated using an unconditional logistic regression model. The results were considered statistically significant when $\mathrm{p}<0.05$.

\section{Results}

This study included 104 patients with gastric cancer (44 in females and 60 in males) and 100 cancer-free control subjects (38 in female and 62 in males) (Table 1). There were no statistically significant differences in the distributions of sex and age between patients and controls ( $p>0.05$ ). The length of PCR products for $\mathrm{p} 53$ codon 72 Pro and Arg alleles was 177 and 141 bp, respectively (Figure 1). The frequencies of p53 R72P genotypes have been estimated using an allele specific PCR (AS-PCR) that specifically detects either the $\mathrm{p} 53$ proline or arginine allele for codon 72 . The allelic frequencies in the patient group were Arg 48\% and Pro 52\%; however, the difference did not reach statistical significance using odds ratio test $(p=0.25)$. The distribution of genotypes and polymorphic alleles in patients and controls are summarized in Table 2. No significant difference was observed regarding the P53 genotype frequencies at codon 72 between patients. Among the 104 Gastric cancer patients, 6 (5.7\%) Arg homozygotes, 10 (9.7\%) Pro homozygotes and $88(84.6 \%)$ Arg/Pro heterozygotes were identified. From the controls 27 (27\%) were Arg homozygotes, 15 (15\%) Were Pro homozygotes and $58(58 \%)$ were heterozygous. The 
homozygous genotype frequencies were $16(15.4 \%)$ in cancer cases and 42 (42\%) in control subjects.

AS-PCR was also used for genotyping MDM2 SNP309, which products have 168 bp (G allele) and 121 bp (T allele) in length (Figure 2). The $G$ allele was significantly associated with the presence of gastric cancer $(p=0.01)$. The frequency of GG, TG and TT genotypes of

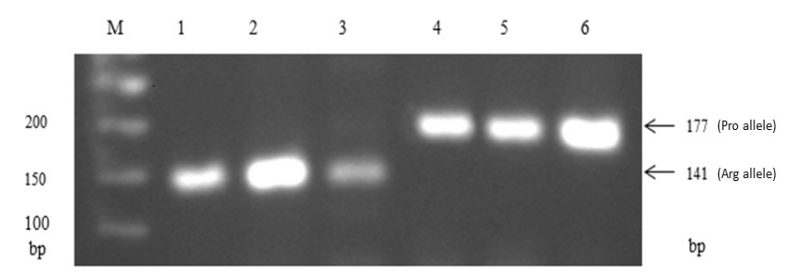

Figure 1.p53 R72P PCR Products Stained by Ethidium Bromide on 2\% Agarose Gel Electrophoresis. Lanes: (M), 50- bp DNA marker; (1-3), 141-bp and (3-6), 177-bp fragments amplified from different samples

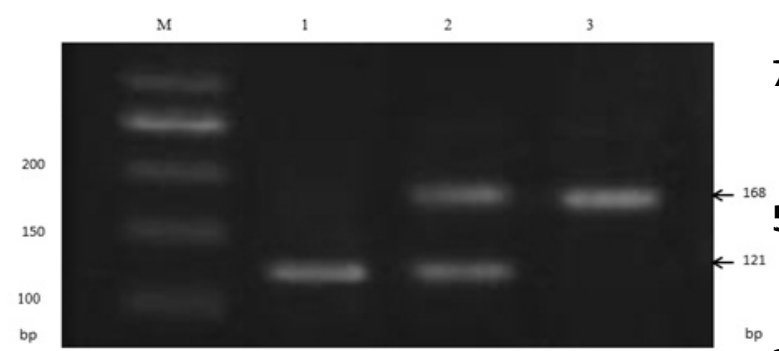

Figure 2. MDM2 SNP309 PCR Product Stained by Ethidium Bromide on 2\% Agarose Gel-Electrophoresis. $\mathrm{T} / \mathrm{T}$ homozygote had a single band of $121 \mathrm{bp}$ (lane 1). T/G heterozygote had two bands of 121 and 168 bp (lane 2) and G/G homozygote had a single fragment of 168 bp (lane 3 )

Table 1. Characteristics of Gastric Cancer Patients and Cancer-free Controls

\begin{tabular}{lccc}
\hline Variable & $\begin{array}{c}\text { Patient } \\
(\mathrm{n}=104) \mathrm{n}(\%)\end{array}$ & $\begin{array}{c}\text { Healthy control } \\
(\mathrm{n}=100) \mathrm{n}(\%)\end{array}$ \\
\hline \multicolumn{2}{l}{ Mean age, years $\left( \pm \mathrm{SD}^{\mathrm{a}}\right)$} & $67.8( \pm 8.84)$ & $64.2( \pm 5.14)$ \\
Age, years & $<50$ & $2(1.93)$ & $16(16)$ \\
& $50-65$ & $22(21.15)$ & $66(66)$ \\
& $>65$ & $80(76.92)$ & $18(18)$ \\
& Males & $60(57.7)$ & $62(62)$ \\
& Females & $44(42.3)$ & $38(38)$ \\
\hline *SD: Standard diviation
\end{tabular}

Table 2. Distribution of TP53 Codon 72 and MDM2 SNP309 Genotypes in GC Cases and Controls

\begin{tabular}{|c|c|c|c|c|}
\hline & $\begin{array}{c}\text { GC Cases } \\
(n=104) n(\%)\end{array}$ & $\begin{array}{c}\text { Controls } \\
(\mathrm{n}=100) \mathrm{n}(\%)\end{array}$ & $\begin{array}{c}\text { ORa } \\
(95 \% \mathrm{CI})\end{array}$ & $\mathrm{p}$ value ${ }^{\mathrm{b}}$ \\
\hline \multicolumn{5}{|l|}{ p53P72R } \\
\hline Pro allele & $108(52)$ & $88(44)$ & 1 (Ref) & \\
\hline Arg allele & $100(48)$ & $112(56)$ & $1.37(0.79-2.4)$ & 0.25 \\
\hline $\mathrm{P} / \mathrm{P}$ & $10(9.7)$ & $15(15)$ & $0.37(0.11-1.2)$ & 0.1 \\
\hline $\mathrm{P} / \mathrm{R}$ & $88(84.6)$ & $58(58)$ & $0.15(0.05-0.39)$ & 0.001 \\
\hline $\mathrm{R} / \mathrm{R}$ & $6(5.7)$ & $27(27)$ & $0.29(0.06-1.4)$ & 0.12 \\
\hline $\mathrm{R} / \mathrm{R}+\mathrm{P} / \mathrm{R}$ & $94(90.4)$ & $85(85)$ & $1.404(0.47-4.18)$ & 0.54 \\
\hline \multicolumn{5}{|c|}{ MDM2SNP309 } \\
\hline T allele & $47(45)$ & $126(63)$ & $1(\operatorname{Ref})$ & \\
\hline $\mathrm{G}$ allele & $57(55)$ & $74(37)$ & $2.08(1.37-4.34)$ & 0.01 \\
\hline $\mathrm{T} / \mathrm{T}$ & $8 \quad(7.7)$ & $30(30)$ & 1 (Ref) & \\
\hline $\mathrm{T} / \mathrm{G}$ & $78(75)$ & $66(66)$ & $4.43(1.33-14.66)$ & 0.01 \\
\hline $\mathrm{G} / \mathrm{G}$ & $18(17.3)$ & 4 (4) & $16.87(2.55-111)$ & 0.003 \\
\hline $\mathrm{G} / \mathrm{G}+\mathrm{T} / \mathrm{G}$ & $96(92.3)$ & $70(70)$ & $5.00(1.5-16.8)$ & 0.006 \\
\hline
\end{tabular}

MDM2 SNP309 polymorphism in the controls was $4 \%$, $66 \%$ and $30 \%$, respectively, while those in gastric cancer patients were $17.3 \%, 75 \%$ and $7.7 \%$ (Table 2).

\section{Discussion}

The p53 tumor suppressor protein is a classic gatekeeper of cellular fate (Ko and Prives, 1996; Vogelstein et al., 2000). Although loss of p53 function causes tumor susceptibility, hyperactivation of p53 is lethal; therefore, p53 activity must be severely regulated for normal tissue homeostasis maintenance (Wade et al., 2010). MDM2 is a crucial negative regulator of $\mathrm{p} 53$, that promote its degradation, as disclosed by models in which deletion of $M D M 2$ gene is lethal in a p53-dependent manner (Marine et al., 2006; Ren et al., 2013).

Several epidemiological studies have evaluated the connection of p53 R72P, MDM2 SNP309 and risk of different types of cancer (Marine et al., 2006; Sadeghi et al., 2013; Song et al., 2013). In the current study the p53 R72P and MDM2 SNP309 polymorphisms were investigated in a series of 104 patients of GC, and in 100 population matched controls in order to verify the impact of P53 and MDM2 variants on the risk of tumor development in Iranian GC patients.

Our results showed no significant differences in the genotype distribution of the p53 R72P polymorphism between patients and controls, and trivial increase in the frequency of the proline alleles among patients and the arginine allele among controls was not significant. This observation is in agreement with previous study reporting no association between $\mathrm{p} 53 \mathrm{R} 72 \mathrm{P}$ polymorphism and GC cancer in a group of 224 Iranian patients with gastrointestinal cancers (92 with GC and 132 with colorectal cancer) and in 163 healthy controls (Mojtahedi et al., 2010). Hamajima and coworkers found no association between the Pro allele and the risk of gastrointestinal cancer in Japanese patients (Hamajima et al., 2002). Conversely, a moderate increase in the risks of gastric cancer and colorectal cancer with higher frequency of Pro/Pro genotype was observed among Korean patients (Wo et al., 2011), and also the association between p53 R72P and GC observed among Chinese Han patients, was significant (Zhou et al., 2010). 2012 updated metaanalysis about the association of the p53 R72P and GC risk was done among twenty-eight studies, 16 of them were conducted in an Asian population $(5,617$ cases and 6,347 controls), 11 in a Caucasian population $(1,158$ cases and 2,745 controls) and one in a mixed population (84 cases and 185 controls). This study indicated that the p53 codon $72 \mathrm{Arg} / \mathrm{Arg}$ genotype is associated with a moderately decreased risk of GC in Asians (OR=0.87, $95 \% \mathrm{CI}=0.78-0.97, \mathrm{p}=0.01)$, and those differences in genotype distribution may be associated with cancer stage, location, differentiation and metastasis. Although, among Caucasians no significant difference in genotype distribution (Arg/Arg: $\mathrm{OR}=1.03,95 \% \mathrm{CI}=0.85-1.26$; $\mathrm{Arg}$ / Pro: $\mathrm{OR}=1.03,95 \% \mathrm{CI}=0.80-1.32$; Pro/Pro: $\mathrm{OR}=0.88$, $95 \% \mathrm{CI}=0.64-1.21)$ was observed, suggesting that the p53 R72P may have no significant influence on the GC risk in Caucasian populations. This may be as a result 
of the significant difference in the distribution of this polymorphism between races (Liu et al., 2012).

To our knowledge, no study has been published about the association of MDM2 SNP309 polymorphism with GC in Iranian population per se. The frequencies of $M D M 2$ SNP309 G/G homozygous (17.3\%) and T/G heterozygous (75\%) genotypes were significantly higher among GC patients in comparison to controls $(\mathrm{p}=0.003$ and $\mathrm{p}=0.01$, respectively). The MDM2 SNP309 T/T homozygous genotype in $\mathrm{GC}$ was lower (7.7\%) than that observed in controls $(30 \%)$.

There are some reports assessing the MDM2 SNP309 in gastric cancer. In a case-control study including 438 controls and 410 patients with sporadic gastric carcinoma, MDM2 SNP309 genotyping showed significant association between SNP309 with gastric carcinogenesis. The risk of overall gastric carcinoma for SNP309 (G/G) was significantly increased when compared with $\mathrm{T}$ carriers $(\mathrm{p}=0.039)$ (Ohmiya et al., 2006).

A meta-analysis of MDM2 SNP309 and tumor vulnerability indicated that $M D M 2$ SNP309 is a plausible tumor biomarker. The reviewed data indicated that variant homozygote 309GG and heterozygote 309TG were associated with a significant increased risk of most tumor types (homozygote comparison: odds ratio $(\mathrm{OR})=1.25$, $95 \%$ confidence interval $(\mathrm{CI})=1.13-1.37$; heterozygote comparison: $\mathrm{OR}=1.10,95 \% \mathrm{CI}=1.03-1.17$ ) (Wo et al., 2011).

The p53 could be activated in cellular stresses, and MDM2 SNP309 can act as a key mediator upon this response. For instance, 5- to 14-fold raises in p53 protein level occur in SNP309 TT cells upon the stress signals; whereas only 2- to 3-fold raises occur in SNP309 GG cells (Bond et al., 2005b). Another study indicated that MDM2 targets p53 for degradation only in stressed GG cells, and in non-stressed cells, increased levels of MDM2 do not further decrease the levels of wide-type $\mathrm{p} 53$ protein (Bond et al., 2004).

In conclusion, these results provide the first evidence from Iran that showed the MDM2 SNP309 polymorphism is a risk factor for gastric cancer. Conversely, the p53 R72P seems not to be a potential risk factor for development of GC among the Iranian population. Since genetic polymorphisms often vary among different ethnic groups, the different results in different populations may be due to different genetic background.

\section{References}

Atrkar-Roushan Z, Kazemnejad A, Mansour-Ghanaei F, et al (2013). Trend analysis of gastrointestinal cancer incidences in guilan province: comparing rates over 15 years. Asian Pac $J$ Cancer Prev, 14, 7587-93.

Bond GL, Hu W, Bond EE, et al (2004). A single nucleotide polymorphism in the $<\mathrm{i}>M D M 2</ \mathrm{i}>$ promoter attenuates the p53 tumor suppressor pathway and accelerates tumor formation in humans. Cell, 119, 591-602.

Bond GL, Hu W, Levine A (2005a). A single nucleotide polymorphism in the $M D M 2$ gene: from a molecular and cellular explanation to clinical effect. Cancer Res, $\mathbf{6 5}$, 5481-4.

Bond GL, Hu W, Levine AJ (2005b). MDM2 is a central node in the p53 pathway: 12 years and counting. Current Cancer Drug Targets, 5, 3-8.

Fakharzadeh S, Trusko S, George D (1991). Tumorigenic potential associated with enhanced expression of a gene that is amplified in a mouse tumor cell line. EMBO J, 10, 1565 .

Fallah M (2007). Cancer incidence in five provinces of Iran: Ardebil, Gilan, Mazandaran, Golestan and Kerman, 19962000.

Hamajima N, Matsuo K, Suzuki T, et al (2002). No associations of $<$ i $>$ p73</i $>$ G4C14-to-A4T14 at exon 2 and $<$ i $>$ p $53<1$ i $>$ Arg 72Pro polymorphisms with the risk of digestive tract cancers in Japanese. Cancer letters, 181, 81-5.

Harris CC, Hollstein M (1993). Clinical implications of the p53 tumor-suppressor gene. New Engl J Med, 329, 1318-27.

Harris N, Brill E, Shohat O, et al (1986). Molecular basis for heterogeneity of the human 533 protein. Molecular Cellular Biol, 6, 4650-6.

Ko LJ, Prives C (1996). p53: puzzle and paradigm. Genes Development, 10, 1054-72.

Liu K-J, Qi H-Z, Yao H-L, et al (2012). An updated meta-analysis of the $\mathrm{p} 53$ codon 72 polymorphism and gastric cancer risk. Molecular Biology Reports, 39, 8265-75.

Marine J-C, Francoz S, Maetens M, et al (2006). Keeping p53 in check: essential and synergistic functions of $\mathrm{Mdm} 2$ and Mdm4. Cell Death Differentiation, 13, 927-34.

Matlashewski G, Tuck S, Pim D, et al (1987). Primary structure polymorphism at amino acid residue 72 of human p53. Molecular Cellular Biol, 7, 961-3.

Menin C, Scaini MC, De Salvo GL, et al (2006). Association between MDM2-SNP309 and age at colorectal cancer diagnosis according to p53 mutation status. J Natl Cancer Inst, 98, 285-8.

Mojtahedi Z, Haghshenas M, Hosseini S, et al (2010). p 53 codon 72 polymorphism in stomach and colorectal adenocarcinomas in Iranian patients. Indian J Cancer, 47, 31 .

Momand J, Zambetti GP, Olson DC, et al (1992). The< i> mdm- $2</ i>$ oncogene product forms a complex with the p53 protein and inhibits p53-mediated transactivation. Cell, 69, 1237-45.

Moradi MT, Salehi Z, Asl SF, et al (2013). Helicobacter pylori infection and MDM2 SNP309 association with gastric cancer susceptibility. Genet Test Mol Biomarkers, 17, 794-8.

Oh MG, Kim JH, Han MA, et al (2014). Family history and survival of patients with gastric cancer: a meta-analysis. Asian Pac J Cancer Prev, 15, 3465-70.

Ohmiya N, Taguchi A, Mabuchi N, et al (2006). MDM2 promoter polymorphism is associated with both an increased susceptibility to gastric carcinoma and poor prognosis. J Clin Oncol, 24, 4434-40.

Pei D, Zhang Y, Zheng J (2012). Regulation of p53: a collaboration between Mdm2 and Mdmx. Oncotarget, 3, 228.

Poyurovsky MV, Prives C (2006). Unleashing the power of p53: lessons from mice and men. Genes Development, 20, 125-31.

Ren Y-W, Yin Z-H, Wan Y, et al (2013). P53 Arg72Pro and MDM2 SNP309 polymorphisms cooperate to increase lung adenocarcinoma risk in Chinese female non-smokers: A Case Control Study. Asian Pac J Cancer Prev, 14, 5415-20.

Sadeghi RN, Damavand B, Vahedi M, et al (2013). Detection of p53 common intron polymorphisms in patients with gastritis lesions from Iran. Asian Pac J Cancer Prev, 14, 91-6.

Sakamuro D, Sabbatini P, White E, et al (1997). The polyproline region of p53 is required to activate apoptosis but not growth arrest. Oncogene, 15, 887-98.

Somi MH, Golzari M, Farhang S, et al (2014). Gastrointestinal cancer incidence in East Azerbaijan, Iran: update on 5 year incidence and trends. Asian Pac J Cancer Prev, 15, 3945. 
Song B, Duan Z-Y, Zhong Y-H, et al (2013). Meta-analysis of the $M D M 2$ T309G polymorphism and gastric cancer risk. Asian Pac J Cancer Prev: APJCP, 14, 6649-51.

Storey A, Thomas M, Kalita A, et al (1998). Role of a p53 polymorphism in the development of human papillomavirus-associated cancer. Nature, 393, 229-34.

Tahara E (1993). Molecular mechanism of stomach carcinogenesis. J Cancer Res Clin Oncol, 119, 265-72.

Tian X, Tian Y, Ma P, et al (2013). Association between MDM2 SNP309 T> G and risk of gastric cancer: a meta-analysis. Asian Pac J Cancer Prev, 14, 1925-9.

Vogelstein B, Lane D, Levine AJ (2000). Surfing the p53 network. Nature, 408, 307-10.

Wade M, Wang YV, Wahl GM (2010). The p53 orchestra: Mdm2 and Mdmx set the tone. Trends Cell Biol, 20, 299-309.

Walker KK, Levine AJ (1996). Identification of a novel p53 functional domain that is necessary for efficient growth suppression. Proc Natl Academy of Sciences, 93, 15335-40.

Whibley C, Pharoah PD, Hollstein M (2009).p53 polymorphisms: cancer implications. Nature Reviews Cancer, 9, 95-107.

Wo X, Han D, Sun H, et al (2011). < i $>$ MDM2</i > SNP309 contributes to tumor susceptibility: A meta-analysis. $J$ Genetics Genomics, 38, 341-50.

Zhou Y, Li N, Zhuang W, et al (2010). p53 Codon 72 polymorphism and gastric cancer risk in a Chinese Han population. Genetic Testing Molecular Biomarkers, 14, 829-33. 